\title{
Quality of Caesarean Sections in Rural Sub-Saharan Africa: A Prospective Study in Cameroon
}

\author{
Jean Dupont Ngowa Kemfang ${ }^{*}{ }^{(\mathbb{D}}$, Jovanny Tsuala Fouogue ${ }^{2} \mathbb{( D}^{\circ}$, Adeline Christel Gwet ${ }^{3}$, \\ Arouna Ngapagna Njayou ${ }^{3}$, Bruno Kenfack ${ }^{2}$, Loic Meukem Tatsipie ${ }^{1}$, Christiane Nsahlai ${ }^{1}$, \\ Henri Donald Mutarambirwa ${ }^{4}$, Pamela Leonie Fouogue Nzogning Manebou ${ }^{5}$, Pierre Marie Tebeu ${ }^{1}$
}

\author{
${ }^{1}$ Department of Obstetrics and Gynaecology, Faculty of Medicine and Biomedical Sciences of the University of Yaounde 1, \\ Yaounde, Cameroon \\ ${ }^{2}$ Department of Obstetrics, Gynaecology and Maternal Health, Faculty of Medicine and Pharmaceutical Sciences of the University \\ of Dschang, Dschang, Cameroon \\ ${ }^{3}$ Institute of Health Science, University of Montagnes, Bangangte, Cameroon \\ ${ }^{4}$ Saint Vincent de Paul Hospital, Dschang, Cameroon \\ ${ }^{5}$ Department of Translation, Administrative Court of Bafoussam, Bafoussam, Cameroon \\ Email: *jdkemfang@yahoo.fr
}

How to cite this paper: Kemfang, J.D.N., Fouogue, J.T., Gwet, A.C., Njayou, A.N., Kenfack, B., Tatsipie, L.M., Nsahlai, C., Mutarambirwa, H.D., Manebou, P.L.F.N. and Tebeu, P.M. (2021) Quality of Caesarean Sections in Rural Sub-Saharan Africa: A Prospective Study in Cameroon. Open Journal of Obstetrics and Gynecology, 11, 1361-1377.

https://doi.org/10.4236/ojog.2021.1110127

Received: August 15, 2021

Accepted: October 17, 2021

Published: October 20, 2021

Copyright $\odot 2021$ by author(s) and Scientific Research Publishing Inc. This work is licensed under the Creative Commons Attribution International License (CC BY 4.0).

http://creativecommons.org/licenses/by/4.0/

\section{(c) (i) Open Access}

\begin{abstract}
Introduction: Caesarean section (CS) is a major reproductive health intervention to improve maternal and foetal outcomes if appropriately performed. This study aimed to assess the quality of Caesarean sections (CS) in a rural setting in Cameroon. Materials and Methods: A prospective study conducted in 3 hospitals from February $1^{\text {st }} 2020$ to April $30^{\text {th }} 2020$. One hundred and twenty women who had a CS were included. Data were grouped into 5 categories: 1) Sociodemographic and obstetrical characteristics, 2) Geographic and financial access, 3) Diagnostic procedures, 4) Operative parameters and 5) Post-operative parameters. The Dujardin's model and context-relevant criteria served to construct the quality score. The scale was $0-20$ and scores $\leq 15$ were considered as unacceptable quality while those $>15$ were considered as acceptable quality CS. Logistic regressions permitted to measure associations. Results: There were 538 deliveries and 120 (22.3\%) CS. The mean (SD) gestational age was 38.7 (2.6) weeks with extremes of 31 and 43 weeks. Group 5 of the Robson's classification was predominant (35.0\%). Motorbikes were the mode of transport to the maternity for $72.5 \%$ (87/120) of women. No referral was made by ambulance. Only 44 (36.7\%) women had paid the full cost of the CS prior to surgery. In addition, $26(21.6 \%)$ women had a complete clinical examination on admission. The surgical team was not complete ( $<6 \mathrm{staffs})$ in $56(43.3 \%)$ cases. Anaesthesia was done by nurses in all cases. CS was done by
\end{abstract}


a general practitioner and by nurses in $86(71.7 \%)$ and $14(11.7 \%)$ cases respectively. Overall, mean (SD) quality score (QS) was 16.33 (1.60). Sixty six of the 120 (55.3\%) caesarean sections had unacceptable quality CS. Mean (SD) QS was significantly higher in faith-based hospitals than in public hospitals (18.00 (0.91) versus 15.59 (1.24); $\mathrm{P}<0.001)$. Immediate postoperative clinical monitoring was effective only in $66(55 \%)$ of cases. Apgar score was below 7 over 10 in 17 (14.2\%) cases of which 6 freshes still births. No maternal death was recorded and maternal complications were recorded in $14(11.7 \%)$ cases. Conclusion: The quality of CS is generally poor in rural settings in WestCameroon. The quantity and quality of staffs required for Caesarean sections in the hospitals are sometimes insufficient. The poor quality of CS in this region could be addressed using the faith-based hospitals: St Vincent de Paul's Hospital as a model.

\section{Keywords}

Childbirth, Caesarean Section, Robson's Classification, Apgar Score

\section{Introduction}

The world Health Organisation (WHO) has acknowledged that poor quality of care increases maternal and newborn morbidity and mortality and envisions a world where "every pregnant woman and newborn receives quality care throughout the pregnancy, childbirth and the postnatal period" [1] [2]. Worldwide, caesarean section (CS) is the most common obstetrical surgery and a major reproductive health intervention to improve maternal and foetal outcomes if appropriately performed [3]. In Sub-Saharan Africa (SSA), CS rates despite a slight increase over the past two decades remain below the WHO target (5\% - 15\%) and several studies have depicted several shortcomings in terms of quality: appropriateness, safety, access, timeliness, effectiveness and efficiency [3] [4] [5] [6]. As a result, maternal and perinatal mortality rates following CS in Africa are 50 times higher than in high-income countries [4] [7]. That tremendous reality must be addressed through adequate research-informed policies.

There is a significant research gap on the quality of CS in resource poor SubSaharan African settings with widespread task shifting in obstetrical care [3] [8] [9] [10]. In Cameroon, available literature on CS have reported low rates and poor maternal-foetal outcomes but so far no study has specifically assessed the quality of CS [11] [12] [13] [14] [15]. In view of filling that research gap and in line with the WHO's commitment to improve quality of maternal and newborn care in health facilities, this study's primary objective was to assess the quality of CS in a rural setting in a country where the overwhelming majority of literature on CS is based on urban health facilities. The secondary objective was to describe accessibility, pre-operative assessment, operative and post-operative course of CS in this setting. 


\section{Materials and Methods}

\subsection{Design and Setting}

This quality assessment CS study was conducted from February 1, 2020 and April 30, 2020 in three hospitals in the Menoua Division in the West-Region of Cameroon (Dschang District Hospital, the Penka Michel District Hospital and Saint Vincent de Paul Catholic Hospital in Dschang) which is mainly rural and has over 300,000 inhabitants. Two of those health facilities are state-owned: the Dschang District Hospital (DDH) and the Penka Michel District Hospital (PMDH) and the third is faith-based: the Saint Vincent de Paul Hospital in Dschang (SVPH). Those three health facilities manage most of obstetrical emergencies in the Menoua Division.

The maternity of the DDH has a capacity of 27 beds and is led by an obstetrician-gynaecologist assisted by 5 general practitioners, 6 midwives and 5 nurses. The surgical theatre is available round the clock every day and anaesthesia is delivered by trained and/or certified nurses. The DDH's paediatric department has a neonatal unit and is led by a paediatrician. The multifunctional biology laboratory is led by a senior biological engineer. The pharmacy is run by 3 pharmacists and the hospital doesn't have a blood bank. The yearly average number of deliveries was 1412 from 2016 to 2019.

The maternity of the SVPH has a capacity of 16 beds and is headed by a general practitioner assisted by 2 midwifes and 4 nurses. The surgical theatre is available round the clock every day and anaesthesia is delivered by trained and/or certified nurses. The SVPH's paediatric department is led by a general practitioner and doesn't have a neonatal unit. The multifunctional biology laboratory is managed by a biological technician, and carries out only basic tests. The pharmacy is run by a community worker and there is no blood bank. The yearly average number of deliveries was 822 from 2016 to 2019.

The maternity of the PMDH has a capacity of 11 beds and is headed by a general practitioner assisted by 1 midwife and 1 nurse. The surgical theatre is available round the clock every day and anaesthesia is delivered by trained and/or certified nurses. The PMDH's paediatric department is led by a general practitioner and doesn't have a neonatal unit. The biology laboratory is managed by a biological technician and carries out only basic tests. The pharmacy is run by a community worker and there is no blood bank. The yearly average of deliveries was 132 from 2016 to 2019.

\subsection{Participants}

Sampling was exhaustive and consecutive. We prospectively included all women who delivered by caesarean section (after 28 completed weeks of pregnancy) and received postoperative care in the study hospitals between February 1, 2020 and April 30, 2020. The quality of caesarean sections was assessed according to the analytical framework of Dujardin and Delvaux (1998) based on its four pillars (access, diagnosis, procedure, postoperative care of CS) [8]. The quality of cae- 
sarean section was classified as acceptable (very good score: 18-20/20 and good score: $17-16 / 20$ ) or unacceptable (poor score: $14-15 / 20$ and very poor score $\leq 13$ ). Maternal complications (present or absent) and foetal outcome (Apgar score $\geq 7$ over 10 and Apgar score $<7$ over 10) were noted.

Data were collected from hospital records, patients' files and face-to-face interviews. Five categories of variables were retrieved: 1) sociodemographic and obstetrical characteristics (age, level of formal education, habitat, marital status, gravidity, parity, gestational age, total number and timing of antenatal consultations, number and content of obstetrical ultrasounds and number of uterine scars), 2) operative and peri-operative variables (pre-operative assessment: blood pressure, pulse rate, temperature, symphyseal-fundal height, foetal presentation, foetal heart rate, cervical dilatation, state of the foetal membranes, maternal weight and height, estimated foetal weight, clinical pelvimetry, use of partogram, Robson's class, qualification of personnel who indicated the surgery; operative variables: total duration of the caesarean section, incision-extraction duration, availability of the surgical kit, availability and composition of the operative team, type of anaesthesia, qualification of the surgeon, qualification of the anaesthetist, supplementary procedures; postoperative parameters; effectiveness and report of nursing care, delays in caregiving, missed care, duration of postoperative hospital stay, duration of total hospital stay, availability of blood donors, blood transfusion), 3) geographic and financial accessibility to caesarean section (means of transport to the hospital, distance to hospital, mode of admission into the hospital, availability of users' fees for CS, the overall cost of the hospital stay) and 4) maternofoetal outcomes (Apgar's score, birthweight, early neonatal complications, early maternal complications, maternal and neonatal death). We used the Dujardin's model and selected criteria from context-relevant literature to set the quality score (Table 1) [8] [9] [10].

\subsection{Statistics}

Data were entered into a predefined excel sheet (Microsoft Excel 2010 software) analysed using SPSS $^{\circledR}$ (Statistical Package for Social Sciences) 25 software to generate tables of frequencies or $2 \times 2$ tables. Khi2 was used when necessary to compare proportions or Student-test (t-test) when necessary to compare means (replaced by Wilcoxon-test for abnormal distribution). Association between variables was measured using bivariate analyses followed by a multivariate analysis including independent variables having a $\mathrm{P}$-value $<0.05$ on bivariate analysis.

\subsection{Ethical considerations}

The study was approved by the institutional ethics board of the University of "Montagnes" at Bangangté in the West region of Cameroon. Investigators strictly complied with the Helsinki guidelines on research involving human subjects (written informed consent, anonymity, administrative clearance and confidentiality were compulsory). 
Table 1. Quality score for cesarean section.

\begin{tabular}{|c|c|c|c|c|}
\hline Categories & & Indicators & Items & Scores \\
\hline \multirow{4}{*}{$\begin{array}{l}\text { Access to caesarean } \\
\text { section }\end{array}$} & \multirow[t]{4}{*}{2} & \multirow[t]{2}{*}{ geographic access to health facilities } & $<15$ Kilometers & 1 \\
\hline & & & $\geq 15$ kilometers & 0 \\
\hline & & \multirow[t]{2}{*}{ financial access } & No delay due to lack of money & 1 \\
\hline & & & Delay due to lack of money & 0 \\
\hline \multirow[t]{6}{*}{ Preoperative diagnosis } & \multirow[t]{6}{*}{3} & \multirow{2}{*}{$\begin{array}{l}\text { Completeness of pre-operative clinical } \\
\text { assessment }\end{array}$} & $\geq 8$ over $\mathrm{X}$ compulsory ${ }^{\mathrm{b}}$ clinical $^{\mathrm{b}}$ parameters $^{\&}$ & 1 \\
\hline & & & $<8$ over $\mathrm{X}$ compulsory clinical ${ }^{\mathrm{b}}$ parameters ${ }^{\&}$ & 0 \\
\hline & & \multirow{2}{*}{$\begin{array}{l}\text { Qualification of the care provider who } \\
\text { indicated the surgery }\end{array}$} & Obstetrician-Gynaecologist/Midwife/General practitioner & 1 \\
\hline & & & Others & 0 \\
\hline & & \multirow{2}{*}{$\begin{array}{l}\text { Appropriateness of the indication of the } \\
\text { caesarean section }^{d}\end{array}$} & Appropriate (Absolute/Cautiousness/Compulsory) & 1 \\
\hline & & & Inappropriate (convenience/abusive) & 0 \\
\hline \multirow{14}{*}{$\begin{array}{l}\text { Surgical resources and } \\
\text { per-operative } \\
\text { parameters }\end{array}$} & \multirow[t]{14}{*}{7} & \multirow[t]{2}{*}{ Completeness of surgical team } & Complete ( $\geq 6$ staffs $)^{c}$ & 1 \\
\hline & & & Incomplete $(<6 \text { staffs })^{c}$ & 0 \\
\hline & & \multirow[t]{2}{*}{ Availability of a functional surgical theatre } & Available & 1 \\
\hline & & & Unavailable & 0 \\
\hline & & \multirow[t]{2}{*}{ Availability of blood donors } & Available & 1 \\
\hline & & & Unavailable & 0 \\
\hline & & \multirow[t]{2}{*}{ Qualification of the cesarean-provider } & Obstetrician/Surgeon/General practitioner & 1 \\
\hline & & & Nurse, non-health professionals & 0 \\
\hline & & \multirow[t]{2}{*}{ Qualification of the anaesthetist } & Certified anaesthetist doctor/or nurse & 1 \\
\hline & & & Others non certified nurse, & 0 \\
\hline & & \multirow[t]{2}{*}{ Intra-operative complications } & No complication & 1 \\
\hline & & & Any complication & 0 \\
\hline & & \multirow{2}{*}{$\begin{array}{l}\text { Availability of the cesarean kit (surgical and } \\
\text { anaesthetic) }\end{array}$} & Available & 1 \\
\hline & & & Unavailable & 0 \\
\hline \multirow{14}{*}{$\begin{array}{l}\text { Post-operative care } \\
\text { and outcome }\end{array}$} & \multirow[t]{14}{*}{7} & \multirow[t]{2}{*}{ Intensive monitoring within the first two hours } & Effective & 1 \\
\hline & & & Ineffective & 0 \\
\hline & & \multirow[t]{2}{*}{ Duration of postoperative hospital stay } & $\leq 7$ days & 1 \\
\hline & & & $>7$ days & 0 \\
\hline & & \multirow[t]{2}{*}{ Lateness or omission of care/drug administration } & No & 1 \\
\hline & & & Yes & 0 \\
\hline & & \multirow[t]{2}{*}{ Maternal postoperative complications } & No complication & 1 \\
\hline & & & Any complication & 0 \\
\hline & & \multirow{2}{*}{$\begin{array}{l}\text { Compliance of nursing care with medical } \\
\text { instructions }\end{array}$} & Compliant & 1 \\
\hline & & & Not compliant & 0 \\
\hline & & \multirow[t]{2}{*}{$5^{\text {th }}$ minute Apgar score } & $\geq 7 / 10$ & 1 \\
\hline & & & $<7 / 10$ & 0 \\
\hline & & \multirow[t]{2}{*}{ Materno-neonatal survival } & Mother and child(ren) alive & 2 \\
\hline & & & Maternal or neonatal death & 0 \\
\hline
\end{tabular}

${ }^{\mathrm{a}} \mathrm{N}$ : number of indicators; ${ }^{\mathrm{b}} 8$ clinical parameters (blood pressure, pulse rate, temperature, symphyseal-fundal height, foetal presentation, foetal heart tone, cervical dilation, state of the foetal membranes); ${ }^{c} 6$ staffs (surgeon, assistant-surgeon, anaesthetist, assistant-anaesthetist, midwife, scrub technician); ${ }^{\mathrm{d} A p-}$ propriateness of the CS indication was determined by and independent Gynaecologist-Obstetrician working in the region where the study was conducted. 


\section{Results}

During the study period, there were 538 deliveries and 120 (22.3\%) CS. Figure 1 describes the participants' inclusion process. Seventy-eight of the 120 (65.0\%) CS were emergency procedures and 83 (69.2\%) of CS were recorded in state-owned hospitals (Dschang District Hospital and Penka-Michel District Hospital) and 37 (30.8\%) were registered in the faith-based hospital (Saint Vincent de Paul Hospital of Dschang).

\section{Socio-demographical and obstetrical characteristics of participants}

Table 2 describes the characteristics of participants. Mean (standard deviation (SD)) age was 27.6 (6.3) years with extremes of 17 and 42 years. Participants between age 15 - 24 years accounted for $41.7 \%(50 / 120)$ of the sample size. The level of education of participants was secondary for $51.7 \%$ and tertiary for $47.5 \%$ of participants. The mean pre-operative parity (SD) was $1.56(1.48)$ and primiparous accounted for $21.7 \%(26 / 120)$ of the sample size. The mean (SD) gestational age was 38.7 (2.6) with extremes of 31 and 43 weeks. One hundred and fourteen (95.0\%) participants did antenatal consultation during the third trimester and $38.4 \%(46 / 120)$ had a previous caesarean section. The following Robson's group were predominant: group $5(35.0 \%)$, group $1(17.5 \%)$ and group 3 (17.5\%).

\section{Access to caesarean section and pre-operative assessment}

Table 3 illustrates assessments for access to caesarean section and pre-operative clinical evaluation of participants, $11.5 \%$ (14/120) of participants lived more than 15 kilometers away from the hospital. Motorbikes were the mode of transport to the maternity for $72.5 \%(87 / 120)$ of participants. None of the women was carried to the hospital with an ambulance. Patients and families who could totally afford the fees for caesarean section constituted $36.7 \%(44 / 120)$. After the

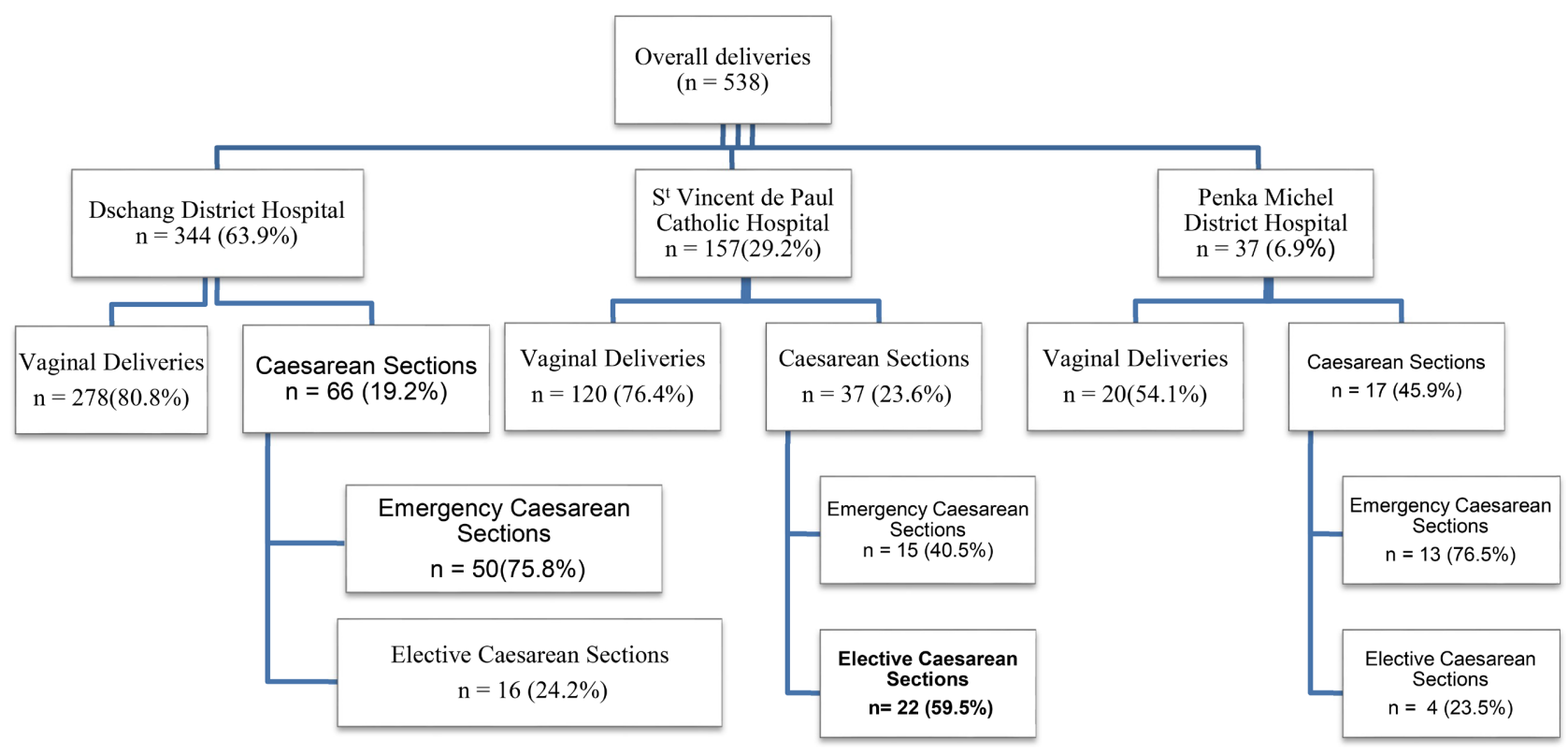

Figure 1. Selection of participants in the three hospitals. 
Table 2. Characteristics of participants

\begin{tabular}{|c|c|c|c|c|}
\hline Variables & $\begin{array}{l}\text { Total } \\
\mathrm{n}(\%)\end{array}$ & $\begin{array}{l}\mathrm{DDH} \\
\mathrm{n}(\%)\end{array}$ & $\begin{array}{l}\text { PMDH } \\
\text { n (\%) }\end{array}$ & $\begin{array}{l}\text { SVPH } \\
\text { n (\%) }\end{array}$ \\
\hline \multicolumn{5}{|l|}{ Age (years) } \\
\hline $15-24$ & $50(41.7)$ & $23(34.8)$ & $8(47.1)$ & $19(51.4)$ \\
\hline $25-34$ & $48(40.0)$ & $28(42.4)$ & $9(52.9)$ & $11(29.7)$ \\
\hline $35-44$ & $22(18.3)$ & $15(22.7)$ & $0(0.0)$ & $7(18.9)$ \\
\hline \multicolumn{5}{|l|}{ Marital status } \\
\hline In couple without formal wedding & $81(67.5)$ & $41(62.1)$ & $10(58.8)$ & $30(81.1)$ \\
\hline Married with formal wedding & $39(32.5)$ & $25(39.1)$ & $7(41.2)$ & $7(18.9)$ \\
\hline \multicolumn{5}{|l|}{ Occupation } \\
\hline Student & $36(30.0)$ & $17(25.7)$ & $2(11.8)$ & $17(45.7)$ \\
\hline Public sector & $11(9.2)$ & $7(10.6)$ & $2(11.8)$ & $2(5.4)$ \\
\hline Private sector (formal) & $7(5.8)$ & $4(6.1)$ & $1(5.9)$ & $2(5.4)$ \\
\hline Private sector (informal) & $28(23.3)$ & $18(23.7)$ & $3(17.6)$ & $7(18.9)$ \\
\hline Unemployed & $38(31.7)$ & $20(30.3)$ & $9(52.9)$ & $9(24.3)$ \\
\hline \multicolumn{5}{|l|}{ Level of education } \\
\hline Primary & $1(0.8)$ & $0(0.0)$ & $0(0.0)$ & $1(2.7)$ \\
\hline Secondary & $62(51.7)$ & $35(53.0)$ & $12(70.6)$ & $15(40.5)$ \\
\hline University & $57(47.5)$ & $31(47.0)$ & $5(29.4)$ & $21(56.8)$ \\
\hline \multicolumn{5}{|l|}{ Parity } \\
\hline 0 & $26(21.7)$ & $12(18.2)$ & $6(35.3)$ & $8(21.6)$ \\
\hline 1 & $47(39.2)$ & $26(39.4)$ & $7(41.2)$ & $14(37.8)$ \\
\hline $2-3$ & $37(30.8)$ & $19(28.8)$ & $4(23.5)$ & $14(37.8)$ \\
\hline $4-7$ & $10(8.3)$ & $9(13.6)$ & $0(0.0)$ & $1(2.7)$ \\
\hline \multicolumn{5}{|l|}{ Number of ANC } \\
\hline $1-3$ & $34(28.3)$ & $20(30.3)$ & $3(17.6)$ & $11(29.7)$ \\
\hline$\geq 4$ & $86(71.7)$ & $46(69.7)$ & $14(82.4)$ & $26(70.3)$ \\
\hline \multicolumn{5}{|l|}{ Distribution of ANC throughout } \\
\hline $1^{\text {st }}$ trimester & $49(40.8)$ & $28(42.4)$ & $8(47.1)$ & $13(35.1)$ \\
\hline $2^{\text {nd }}$ trimester & $115(95.8)$ & $66(100.0)$ & $16(94.1)$ & $33(89.2)$ \\
\hline $3^{\text {rd }}$ trimester & $114(95.0)$ & $63(95.5)$ & $14(82.4)$ & $37(100.0)$ \\
\hline \multicolumn{5}{|l|}{ Previous caesarean section } \\
\hline No & $74(61.6)$ & $36(54.5)$ & $10(58.8)$ & $28(75.7)$ \\
\hline Yes & $46(38.4)$ & $30(45.5)$ & $7(41.2)$ & $9(24.3)$ \\
\hline \multicolumn{5}{|l|}{ Robson's groups } \\
\hline Group 1 & $21(17.5)$ & $8(12.1)$ & $4(23.5)$ & $9(24.3)$ \\
\hline Group 2 & $5(4.2)$ & $2(3.0)$ & $0(0.0)$ & $3(8.1)$ \\
\hline Group 3 & $21(17.5)$ & $13(19.7)$ & $4(23.5)$ & $4(10.9)$ \\
\hline Group 4 & $7(5.8)$ & $3(4.6)$ & $1(5.9)$ & $3(8.1)$ \\
\hline Group 5 & $42(35.0)$ & $27(40.9)$ & $6(35.3)$ & $9(24.3)$ \\
\hline Group 6 & $5(4.2)$ & $3(4.6)$ & $0(0.0)$ & $2(5.4)$ \\
\hline Group 7 & $4(3.3)$ & $2(3.0)$ & $1(5.9)$ & $1(2.7)$ \\
\hline Group 8 & $11(9.2)$ & $5(7.6)$ & $1(5.9)$ & $5(13.5)$ \\
\hline Group 9 & $1(0.8)$ & $1(1.5)$ & $0(0.0)$ & $0(0.0)$ \\
\hline Group 10 & $3(2.5)$ & $2(3)$ & $0(0.0)$ & $1(2.7)$ \\
\hline
\end{tabular}

PMDH: Penka Michel district Hospital, SVPH: Saint Vincent de Paul Hospital, DDH: Dschang District Hospital, ANC: Antenatal Consultation. 
Table 3. Accessibility to caesarean section and pre-operative diagnosis.

\begin{tabular}{|c|c|c|c|c|}
\hline Variables & $\begin{array}{l}\text { Total } \\
\text { n (\%) }\end{array}$ & $\begin{array}{l}\text { HDD } \\
\text { n (\%) }\end{array}$ & $\begin{array}{c}\text { HDPM } \\
\text { n (\%) }\end{array}$ & $\begin{array}{l}\text { HSVP } \\
\text { n (\%) }\end{array}$ \\
\hline \multicolumn{5}{|c|}{ Accessibility to caesarean section } \\
\hline \multicolumn{5}{|l|}{ Distance from the hospital } \\
\hline$\geq 15$ kilometers & $14(11.7)$ & $9(13.6)$ & $1(5.9)$ & $4(10.8)$ \\
\hline$<15$ kilometers & $106(88.3)$ & $57(86.4)$ & $16(94.1)$ & $33(89.2)$ \\
\hline \multicolumn{5}{|l|}{ Mode of transport } \\
\hline Private car & $9(7.5)$ & $5(7.6)$ & $0(0)$ & $4(10.8)$ \\
\hline Public transport car & $22(18.3)$ & $12(18.2)$ & $6(35.3)$ & $4(10.8)$ \\
\hline Motorbike & $87(72.5)$ & $49(74.2)$ & $9(52.9)$ & $29(78.4)$ \\
\hline Walking & $2(1.7)$ & $0(0)$ & $2(11.8)$ & $0(0)$ \\
\hline \multicolumn{5}{|c|}{ Ability to immediately afford the fees for caesarean section } \\
\hline Entirely & $44(36.7)$ & $31(47.0)$ & $5(29.4)$ & $8(21.6)$ \\
\hline Partially & $55(45.8)$ & $48(42.4)$ & $9(52.9)$ & $18(48.6)$ \\
\hline No & $21(17.5)$ & $7(10.6)$ & $3(17.6)$ & $11(29.7)$ \\
\hline \multicolumn{5}{|c|}{ Delay in caesarean section caused by Lack of payment of the fees } \\
\hline No & $120(100.0)$ & $66(100.0)$ & $17(100.0)$ & $37(100.0)$ \\
\hline Yes & $0(0)$ & $0(0)$ & $0(0)$ & $0(0)$ \\
\hline \multicolumn{5}{|l|}{ Admission following referral } \\
\hline Yes & $31(25.8)$ & $13(9.7)$ & $8(47.1)$ & $10(27.0)$ \\
\hline No & $89(74.2)$ & $53(80.3)$ & $9(52.9)$ & $27(73.0)$ \\
\hline \multicolumn{5}{|l|}{ Pre-operative diagnosis } \\
\hline \multicolumn{5}{|c|}{ Documented clinical parameters assessed on admission } \\
\hline $0-3$ & $38(31.7)$ & $22(33.3)$ & $8(47.0)$ & $8(21.6)$ \\
\hline $4-7$ & $56(46.7)$ & $37(56.0)$ & $9(53.0)$ & $20(54.0)$ \\
\hline 8 & $26(21.6)$ & $17(25.7)$ & $0(0.0)$ & $9(24.4)$ \\
\hline \multicolumn{5}{|c|}{ Qualification of the provider who indicated the caesarean } \\
\hline General practitioner & $97(80.9)$ & $47(71.2)$ & $13(76.5)$ & $37(100.0)$ \\
\hline Obstetrician-gynecologist & $19(15.8)$ & $19(28.8)$ & $0(0.0)$ & $0(0.0)$ \\
\hline Midwife & $4(3.3)$ & $0(0.0)$ & $4(23.5)$ & $0(0.0)$ \\
\hline \multicolumn{5}{|c|}{ Appropriateness of the indication of the caesarean section } \\
\hline Appropriate & $120(100)$ & $66(100)$ & $17(100)$ & $37(100)$ \\
\hline Inappropriate & $0(0.0)$ & $0(0.0)$ & $0(0.0)$ & $0(0.0)$ \\
\hline
\end{tabular}

PMDH: Penka Michel district Hospital, SVPH: Saint Vincent de Paul Hospital, DDH: Dschang District Hospital.

indication of CS, none was delayed for because of lack of user's fees for CS. The quarter of participants $31(25.8 \%)$ were referred from lower tier health facilities. Pre-operative clinical assessment was properly documented for $26(21.6 \%)$ cases and was done by a general practitioner in $80.9 \%(97 / 120)$ of cases. All the indications of CS were appropriate. 


\section{Surgical characteristics of caesarean sections}

Table 4 describes operative CS parameters. The average (SD) duration of CS was 40.1 (9.2) minutes ranging from 20 to 60 minutes. Mean (SD) foetal extraction time (skin incision - foetal extraction) was 7.57 (1.99) minutes. The caesarean section set (material for surgery and anaesthesia) and the operating room were immediately available in $100 \%$ and $99 \%$ of cases respectively. The surgical team was not complete ( $<6$ staffs) in $56(43.3 \%)$ cases. Anaesthesia was done by nurses trained on daily anaesthesia practices without a diploma in 17 (14.2\%) cases and by certified nurse anaesthetist in $103(85.8 \%)$ of cases. CS was done by a general practitioner and by nurses in $86(71.7 \%)$ and $14(11.7 \%)$ cases respectively. None of the study hospitals had a blood bank and blood donors were

Table 4. Assessment of surgical parameters of caesarean sections.

\begin{tabular}{|c|c|c|c|c|}
\hline Variables & $\begin{array}{l}\text { Total } \\
\text { n (\%) }\end{array}$ & $\begin{array}{l}\text { HDD } \\
\text { n (\%) }\end{array}$ & $\begin{array}{c}\text { HDPM } \\
\text { n (\%) }\end{array}$ & $\begin{array}{l}\text { HSVP } \\
\text { n (\%) }\end{array}$ \\
\hline \multicolumn{5}{|c|}{ Availability of the operating theatre } \\
\hline Available & $119(99.0)$ & $65(98.5)$ & $17(100.0)$ & $37(100.0)$ \\
\hline Unavailable & $1(1.0)$ & $1(1.5)$ & $0(0.0)$ & $0(0.0)$ \\
\hline \multicolumn{5}{|c|}{ Availability of the caesarean section kit } \\
\hline Available & $120(100.0)$ & $66(100.0)$ & $17(100.0)$ & $37(100.0)$ \\
\hline Unavailable & $0(0.0)$ & $0(0.0)$ & $0(0.0)$ & $0(0.0)$ \\
\hline \multicolumn{5}{|c|}{ Completeness of the surgical team } \\
\hline Yes ( $\geq 6$ staff) & $68(56.7)$ & $28(42.4)$ & $7(41.2)$ & $33(89.2)$ \\
\hline No ( $<6$ staff) & $52(43.3)$ & $38(57.6)$ & $10(58.8)$ & $4(10.8)$ \\
\hline \multicolumn{5}{|l|}{ Qualification of the anesthetist } \\
\hline Certified nurse anesthetist & $103(85.8)$ & $66(100.0)$ & $0(0.0)$ & $37(100.0)$ \\
\hline Nurse trained "on the job" & $17(14.2)$ & $0(0.0)$ & $17(100.0)$ & $0(0.0)$ \\
\hline \multicolumn{5}{|l|}{ Qualification of the surgeon } \\
\hline Obstetrician-gynecologist & $11(9.1)$ & $11(16.7)$ & $0(0.0)$ & $0(0.0)$ \\
\hline Surgeon & $9(7.5)$ & $0(0.0)$ & $0(0.0)$ & $9(24.3)$ \\
\hline General practitioner & $86(71.7)$ & $55(83.3)$ & $3(17.6)$ & $28(75.7)$ \\
\hline Nurse & $14(11.7)$ & $0(0.0)$ & $14(82.4)$ & $0(0.0)$ \\
\hline \multicolumn{5}{|l|}{ Availability blood donors } \\
\hline Available & $2(1.6)$ & $2(3.0)$ & $0(0.0)$ & $0(0.0)$ \\
\hline Unavailable & $118(98.4)$ & $64(97.0)$ & $17(100.0)$ & $37(100.0)$ \\
\hline \multicolumn{5}{|l|}{ Type of anesthesia } \\
\hline General & $7(6.0)$ & $7(10.6)$ & $0(0.0)$ & $0(0.0)$ \\
\hline Spinal & $96(80.0)$ & $59(89.4)$ & $0(0.0)$ & $37(100.0)$ \\
\hline Local followed by general ${ }^{a}$ & $17(14.0)$ & $0(0.0)$ & $17(100.0)$ & $0(0.0)$ \\
\hline
\end{tabular}

alocal anaesthesia performed to dissect the abdominal wall till the peritoneum then general anaesthesia as from the hysterotomy (in view of shortening the duration of exposure of the foetus to ketamine). PMDH: Penka Michel district Hospital, SVPH: Saint Vincent de Paul Hospital, DDH: Dschang District Hospital. 
available during the surgery for $1.6 \%(2 / 120)$ cases. Anaesthesia was spinal in $80.0 \%(96 / 120)$ of cases. Laparotomy was done according to the Pfannenstiel's technique in $97.5 \%$ (117/120 of cases and the time from skin incision to foetal extraction was below 10 minutes in 95.0\% (114/120) of cases.

\section{Post-operative care and materno-foetal outcomes}

Table 5 summarizes the post-operative care and the materno-neonatal outcomes. Postoperative nursing care was compliant with medical prescription in 95.8\% (115/120) cases. Delays in caregiving were observed in $1.7 \%(2 / 120)$ of cases. Intensive immediate postoperative care was not effective in 45.0\% (54/120) of cases. Apgar score was below 7 over 10 in 14.2\% (17) of cases of which 6 freshes still births. No maternal death was recorded and maternal complications were recorded in $11.7 \%$ (14) of cases.

Caesarean section quality scores

Figure 2 and Table 6 show classes of quality scores and mean quality scores respectively. Quality scores were unacceptable for $55.3 \%$ of caesarean sections (scores $\leq 15 / 20$ ). The mean (SD) quality score for the whole sample was 16.33 (1.60). The mean (SD) global quality score in state-owned hospitals was significantly lower than in the faith-based hospital: (15.59 (1.24) versus 18.00 (0.91); p $<0.001)$. The Faith-based hospital had $2.7 \%$ unacceptable quality CS against

Table 5. Assessment of postoperative care and materno-foetal outcome of caesarean sections.

\begin{tabular}{|c|c|c|c|c|}
\hline Variables & $\begin{array}{l}\text { Total } \\
\text { n (\%) }\end{array}$ & $\begin{array}{l}\text { HDD } \\
\mathrm{n}(\%)\end{array}$ & $\begin{array}{c}\text { HDPM } \\
\text { n (\%) }\end{array}$ & $\begin{array}{l}\text { HSVP } \\
\text { n (\%) }\end{array}$ \\
\hline \multicolumn{5}{|c|}{ Intensive monitoring within the 2 first hours of Cesarean section } \\
\hline Effective & $66(55.0)$ & $33(50.0)$ & $11(64.7)$ & $22(59.5)$ \\
\hline Not effective & $54(45.0)$ & $33(50.0)$ & $6(35.3)$ & $15(40.5)$ \\
\hline \multicolumn{5}{|c|}{ Lateness/delay in delivery of care } \\
\hline Yes & $2(1.7)$ & $2(3.0)$ & $0(0.0)$ & $0(0.0)$ \\
\hline No & $118(98.3)$ & $64(97.0)$ & $17(100.0)$ & $37(100.0)$ \\
\hline \multicolumn{5}{|c|}{ Compliance of nursing care with medical instructions } \\
\hline Compliant & $115(95.8)$ & $64(97.0)$ & $14(82.4)$ & $37(100.0)$ \\
\hline Not compliant & $5(4.2)$ & $2(3.0)$ & $3(17.6)$ & $0(0.0)$ \\
\hline \multicolumn{5}{|c|}{ Duration of the post-operative stay } \\
\hline$\leq 7$ days & $112(93.3)$ & $62(94.0)$ & $13(76.5)$ & $37(100.0)$ \\
\hline$\geq 8$ days & $8(6.7)$ & $4(6.0)$ & $4(23.5)$ & $0(0.0)$ \\
\hline \multicolumn{5}{|c|}{$5^{\text {th }}$ minute Apgar Score } \\
\hline$\geq 7$ & $103(85.8)$ & $57(86.4)$ & $3(17.6)$ & $32(86.5)$ \\
\hline$<7$ & $17(14.2)$ & $9(13.6)$ & $14(82.4)$ & $5(13.5)$ \\
\hline \multicolumn{5}{|c|}{ Postoperative maternal complication } \\
\hline Yes & $14(11.7)$ & $12(18.2)$ & $1(5.9)$ & $1(2.7)$ \\
\hline No & $106(88.3)$ & $54(81.8)$ & $16(94.1)$ & $36(97.3)$ \\
\hline
\end{tabular}

PMDH: Penka Michel district Hospital, SVPH: Saint Vincent de Paul Hospital, DDH: Dschang District Hospital. 
78.3\% in state-owned hospitals.

Partial quality scores were also significantly higher in faith-based hospitals than in state-owned hospitals: pre-operative assessment, surgical parameters and post-operative care (Table 6). Factors associated with poor quality scores are summarized in Table 7. On bivariate analysis the following factors were associated with unacceptable quality of caesarean section: state-owned hospital (cOR (95\%CI): 130 (16.66 - 1014.31); total costs of CS < 180 USD (cOR (95\%CI)): 28.97 (9.81 - 85.56), surgery done by a nurse: (cOR (95\%CI)): 15.78 (1.23 - 27.08); incompleteness of the surgical team (cOR $(95 \% \mathrm{CI})): 2.85$ (1.33 - 6.09); general anaesthesia (cOR (95\%CI)): $3.62(1.37$ - 11.47) and Group 5 of the Robson's classification (cOR (95\%CI)): 1.54(0.72 - 3.32). After adjustment, only state-owned hospitals (aOR (95\%CI): 92.30 (6.33 - 1345.15)) remained associated with unacceptable quality scores.

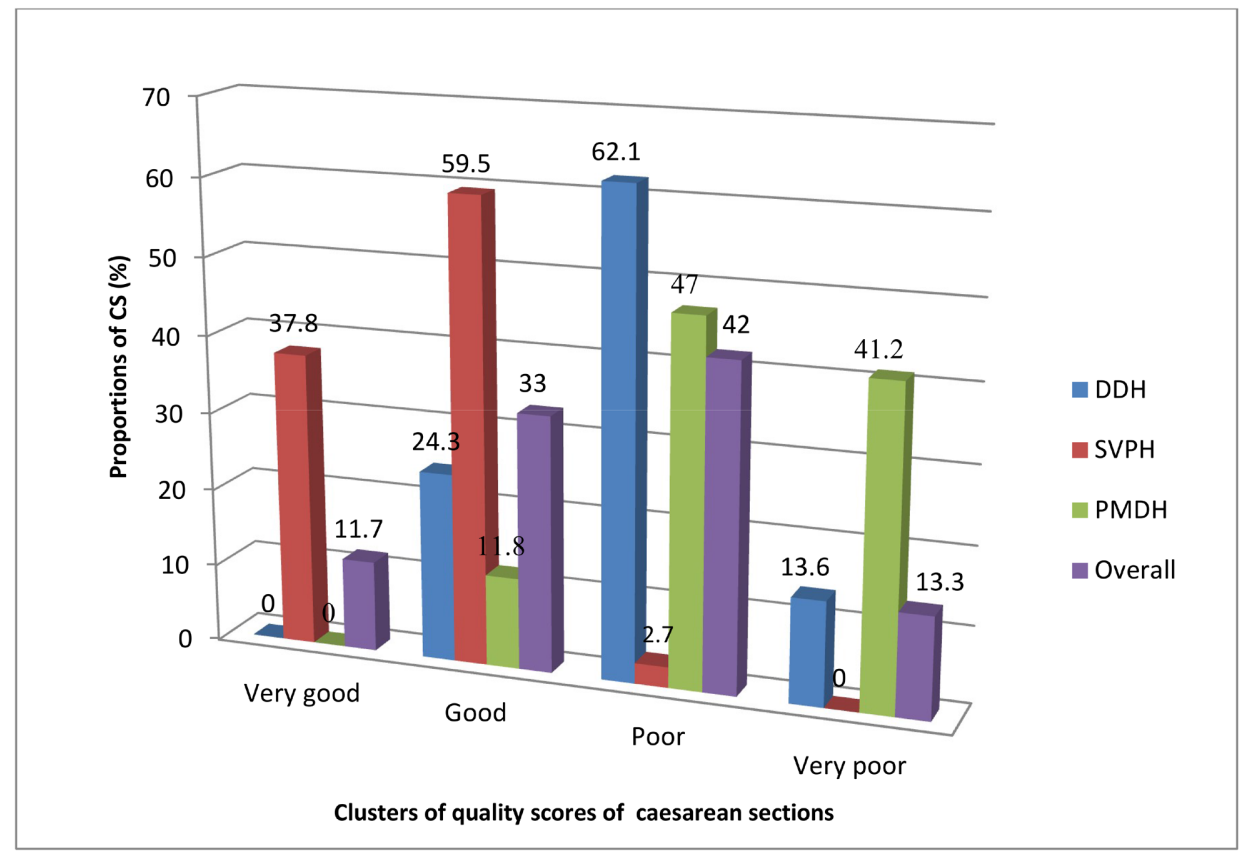

Figure 2. Distribution of patients by clusters of quality scores of CS and health centers.

Table 6. Distribution of caesareans following mean quality scores.

\begin{tabular}{|c|c|c|c|c|c|c|}
\hline Variables & $\begin{array}{c}\text { Total } \\
\text { Mean (SD) }\end{array}$ & $\begin{array}{c}\text { DDH } \\
\text { Mean (SD) }\end{array}$ & $\begin{array}{c}\text { PMDH } \\
\text { Mean (SD) }\end{array}$ & $\begin{array}{c}\text { Faith-based } \\
\text { hospital (SVPH) } \\
\text { Mean (SD) }\end{array}$ & $\begin{array}{c}\text { State-owned } \\
\text { hospitals (DDH } \\
\text { and PMDH) } \\
\text { Mean (SD) }\end{array}$ & $\begin{array}{c}\text { P-value } \\
\text { (State-owned Vs } \\
\text { Faith-based } \\
\text { hospital) }\end{array}$ \\
\hline Access (Scores/2) & $1.88(0.32)$ & $1.86(0.35)$ & $1.94(0.24)$ & $1.89(0.32)$ & $1.88(0.33)$ & 0.66 \\
\hline Diagnosis (Scores/3) & $2.23(0.43)$ & $2.11(0.31)$ & $2.060 .24)$ & $2.54(0.51)$ & $2.10(0.30)$ & 0.00 \\
\hline Surgical parameters (Scores/7) & $5.41(0.62)$ & $5.32(0.47)$ & $4.65(0.70)$ & $5.92(0.28)$ & $5.18(0.59)$ & 0.00 \\
\hline Post-operative care (Scores/5) & $4.03(0.87)$ & $3.78(0.74)$ & $3.24(0.90)$ & $4.81(0.40)$ & $3.67(0.80)$ & 0.00 \\
\hline Outcome (scores/ 3) & $2.78(0.52)$ & $2.78(0.52)$ & $2.71(0.69)$ & $2.84(0.44)$ & $2.84(0.55)$ & 0.59 \\
\hline Overall quality scores (over 20) & $16.33(1.60)$ & $15.86(1.01)$ & $14.53(1.51)$ & $18.00(0.91)$ & $15.59(1.24)$ & 0.00 \\
\hline
\end{tabular}


Table 7. Factors associated with unacceptable quality of caesarean section.

\begin{tabular}{|c|c|c|c|c|c|c|}
\hline Variables & $\begin{array}{l}\text { Unacceptable } \\
\text { quality score } \\
\mathrm{N}=66(\%)\end{array}$ & $\begin{array}{l}\text { Acceptable quality } \\
\text { score } \mathrm{N}=54(\%)\end{array}$ & cOR $(95 \% \mathrm{CI})$ & $\mathrm{P}$-value & aOR $(95 \% \mathrm{CI})$ & P-value \\
\hline \multicolumn{7}{|l|}{ Type of Hospital } \\
\hline State-owned & $65(98.5)$ & $18(33.3)$ & $130(16.66-1014.31)$ & 0.00 & $92.3(6.33-1345)$ & 0.001 \\
\hline Faith-based & $1(1.5)$ & $36(66.7)$ & & & & \\
\hline \multicolumn{7}{|c|}{ Admission following referral } \\
\hline Yes & $16(24.2)$ & $15(27.8)$ & $0.83(0.37-1.89)$ & 0.68 & I & I \\
\hline No & $50(75.8)$ & $39(72.2)$ & & & & \\
\hline \multicolumn{7}{|c|}{ Emergency caesarean } \\
\hline Yes & $47(71.2)$ & $44(81.5)$ & $0.56(0.24-1.34)$ & 0.21 & I & / \\
\hline No & $19(28.8)$ & $10(18.5)$ & & & & \\
\hline \multicolumn{7}{|l|}{ Global costs } \\
\hline$<180$ USD & $61(92.4)$ & $16(29.6)$ & $28.97(9.81-85.56)$ & 0.00 & $0.49(0.08-3.17)$ & 0.457 \\
\hline$\geq 180$ USD & $5(7.6)$ & $38(70.4)$ & & & & \\
\hline \multicolumn{7}{|c|}{ Qualification of the surgeon } \\
\hline Nurse & $12(18.2)$ & $2(3.7)$ & $15.78(1.23-27.0)$ & 0.020 & $038(0.05-3.01)$ & 0.362 \\
\hline Physician & $54(81.8)$ & $52(96.3)$ & & & & \\
\hline \multicolumn{7}{|c|}{ Apgar score $\left(5^{\text {th }}\right.$ minute $)$} \\
\hline$<7$ & $10(15.2)$ & $7(13.0)$ & $0.20(0.42-3.39)$ & 0.763 & / & / \\
\hline$\geq 7$ & $56(84.8)$ & $47(87.0)$ & & & & \\
\hline \multicolumn{7}{|c|}{ Early neonatal death } \\
\hline Yes & $5(7.6)$ & $1(1.9)$ & $4.33(0.49-38.36)$ & 0.221 & I & / \\
\hline No & $61(92.4)$ & $53(98.3)$ & & & & \\
\hline \multicolumn{7}{|c|}{ Maternal complication } \\
\hline Yes & $9(13.6)$ & $5(9.3)$ & $1.55(0.47-4.93)$ & 0.572 & I & I \\
\hline No & $57(86.4)$ & $49(90.7)$ & & & & \\
\hline \multicolumn{7}{|c|}{ Distance from the Hospital } \\
\hline$<15 \mathrm{Km}$ & $7(10.6)$ & $7(13.0)$ & $0.80(0.26-2.43)$ & 0.78 & I & I \\
\hline$\geq 15 \mathrm{Km}$ & $59(89.4)$ & $47(87.0)$ & & & & \\
\hline \multicolumn{7}{|l|}{ Number of ANC } \\
\hline$<4$ & $18(27.3)$ & $16(29.6)$ & $0.89(0.0-1.97)$ & 0.84 & / & l \\
\hline$\geq 4$ & $48(72.7)$ & $38(70.4)$ & & & & \\
\hline \multicolumn{7}{|l|}{ Scarred uterus } \\
\hline Yes & $29(43.9)$ & $16(31.5)$ & $1.71(0.80-3.62)$ & 0.189 & I & I \\
\hline No & $37(56.1)$ & $37(68.5)$ & & & & \\
\hline \multicolumn{7}{|c|}{ Completeness of surgical team } \\
\hline No (<6 staffs) & $36(54.5)$ & $16(29.6)$ & $2.85(1.33-6.09)$ & 0.009 & $0.55(0.18-1.67)$ & 0.291 \\
\hline Yes ( $\geq 6$ staffs) & $30(45.5)$ & $38(70.4)$ & & & & \\
\hline \multicolumn{7}{|l|}{ Anaesthesia } \\
\hline General & $19(28.8)$ & $5(9.3)$ & $3.62(1.37-11.47)$ & 0.011 & $1.56(0.34-7.12)$ & 0.17 \\
\hline Spinal & $47(71.2)$ & 49 (90.7) & & & & \\
\hline \multicolumn{7}{|l|}{ Robson's groups } \\
\hline Group 5 & $26(39.4)$ & $16(29.6)$ & $1.54(0.72-3.32)$ & 0.207 & I & I \\
\hline Other groups & $40(60.6)$ & $38(70.4)$ & & & & \\
\hline
\end{tabular}

USD: United States Dollar; ANC: Antenatal consultation. 


\section{Discussion}

Overall, more than half of caesarean sections had unacceptable quality in rural setting at west Cameroon. The CS rate (22.3\%) in this study is 10 -fold higher than the national average, 20 -fold higher than the rural average and similar to CS rates noted in hospitals in the urban Cameroonian areas [3] [6] [11] [13] [14] [15]. This high rate of CS in this milieu could be explained by the referral status of the study hospitals. Like in others studies in Cameroonian hospitals, a high proportion (25.8\%) of women who underwent CS in our study were referred from other health facilities [11] [13] [14] [15]. Similar CS and referral rates were reported in a rural referral hospital in Tanzania [16]. The high proportion of unacceptable quality of CS we found is similar to those reported in several subSaharan African (SSA) countries where it is (inter alia) responsible of the high CS associated maternal and neonatal morbidity [1] [17] [18]. This could be explained by the fact that in SSA countries, there is poor accessibility of CS, poor medical equipment and lack of qualified health professionals.

Sub-group quality scores were significantly different for pre-operative diagnosis, surgical procedure and resources and post-operative care. Though preoperative clinical assessment was completely documented for only one fifth of women in our study, all decisions of CS were appropriate. This is quite different from a large-scale study in Burkina-Faso that reported $24 \%$ of non-medically (inappropriately) indicated CS [19]. Determinants of inappropriate CS in this BurkinaFaso study were (inter alia) urban residence and decision to CS by general practitioners (GPs). This difference from our results could be explained by the rural residence of all our participants. Besides, considering that four fifths and one fifth of CSs in our study were indicated by GPs and obstetricians respectively, we can hypothesise that long-term lone practice in rural resource-poor setting has improved diagnostic skills of our rural GPs above those of urban GPs in the Kabore's series. We can also hypothesize that the very low acceptability of CS in our rural settings led to a selection of parturients such that only or mostly those with absolute indications of CS underwent surgery.

We found that surgical theatre, CS sets and staff were always readily available although blood and blood donors were generally not available. Therefore, challenging the comprehensiveness of emergency of obstetrical care in the study hospitals. This finding is common in SSA with poor medical equipment and lack of qualified health professionals. A striking finding is the difference in staffing of surgical theatre between state-owned and faith-based hospitals. Indeed, the minimum number of surgical staff for CS was not met in more than half of cases in state-owned hospitals versus $10 \%$ of cases in the faith-based hospital. Moreover, general practitioners performed more than two thirds of CSs overall; nurses did $11.7 \%$ of CS. Similarly, anaesthesia was conducted by certified nurses in more than four fifths of cases overall and non-certified nurses conducted anaesthesia in $14.2 \%$ of CS. Similarly, Kruk et al. reported that in districts hospitals of 3 SSA countries, mid-level staff provided more than a third of CS and anaesthesia thus confirming that planned 
task shifting in surgical practice is widespread in SSA [5] [20]. If task shifting is ineluctable to address the huge gap in skilled staff for comprehensive obstetrical care, appropriate training and monitoring are paramount to ensure safe practice and good outcomes of CS inter alia. The higher qualification and availability of staff during surgery in faith-based hospital may explain the lower complication rates we observed (Apgar score < 7: 13.5\% versus 27.7\%; maternal complications: $2.7 \%$ versus $15.7 \%)$. Overall maternal and neonatal outcomes of CS in our rural series were similar to those reported in urban Cameroonian hospitals and in other SSA settings [3] [4] [5] [6] [7] [9] [10] [12] [14] [15]. The way to curb those high rates is certainly through quality improvement. Our study is most likely the first to prospectively assess the quality of CS in Cameroon. Besides revealing the very high proportion of poor quality CS the study provides details on critical components to be targeted in view of addressing that crucial issue. The data used in this study are highly accurate because they were collected within 7 days of the CS from several sources (women, care providers and hospital records). This study has a main limitation. It has been conducted in a single administrative constituency and therefore may not be generalizable to all Cameroonian rural settings.

\section{Conclusion}

Quality of caesarean sections is generally poor in rural settings in West-Cameroon. The quantity and quality of staffs required for Caesarean sections in the hospitals are sometimes insufficient. State-owned hospital is the main factor associated to unacceptable quality of caesarean section, while faith-based hospital seems to have better quality scores. The poor quality of CS in this region could be addressed using the St Vincent de Paul's Hospital as a model.

\section{Ethics Approval and Informed Consent}

The study was approved by the institutional ethics board of the "Université des Montagnes at Bangangte" in the West region of Cameroon (reference: 2020/133/ $\mathrm{UdM} / \mathrm{PR} / \mathrm{CIE})$.

\section{Data Availability (Where Applicable)}

Data supporting this study are available from authors under reasonable request.

\section{Acknowledgements}

Authors are grateful to the staffs of the Dschang District Hospital, the Penka Michel District Hospital and the Saint Vincent de Paul's District Hospital.

\section{Authors' Contributions}

$\begin{array}{ll}\text { Conception } & \text { JDNK, JTF, BK, } \\ \text { Study design } & \text { JDNK, JTF, ACG, } \\ \text { Execution } & \text { JDNK, JTF, ACG, ANN, LMT, } \\ \text { Acquisition of data } & \text { ACG, ANN, LMT, }\end{array}$


Analysis and interpretation of data

Writing

Critical revision

Critical review
JDNK, JTF, ACG, HDM, JDNK, JTF, ACG, JHF,

BK, LMT, CN, PLMFZ

PMT, FYF, JHF

All the authors have approved the final version and have agreed on the journal.

\section{Conflicts of Interest}

The authors declare no conflicts of interest regarding the publication of this paper.

\section{References}

[1] World Health Organization (2016) Standards for Improving Quality of Maternal and Newborn Care in Health Facilities. http://www.who.int

[2] Tuncalp, O., Were, W.M., MacLennan, C., et al. (2015) Quality of Care for Pregnant Women and Newborns-The WHO Vision. BJOG: An International Journal of $O b$ stetrics \& Gynaecology, 122, 1045-1049. https://doi.org/10.1111/1471-0528.13451

[3] Harrison, M.S. and Goldenberg, R.L. (2016) Caesarean Section in Sub-Saharan Africa. Maternal Health, Neonatology and Perinatology, 2, Article No. 6. https://doi.org/10.1186/s40748-016-0033-x

[4] Sobhy, S., Arroyo-Manzano, D., Murugesu, N., et al. (2019) Maternal and Perinatal Mortality and Complications Associated with Caesarean Section in Low-Income and Middle-Income Countries: A Systematic Review and Meta-Analysis. The Lancet, 393, 1973-1982. https://doi.org/10.1016/S0140-6736(18)32386-9

[5] Fistula Care Plus and Maternal Health Task Force (2017) Cesarean Section Safety and Quality in Low-Resource Settings: Report of a Technical Consultation. Fistula Care Plus, New York. https://fistulacare.org/

[6] Benova, L., Cavallaro, F.L. and Campbell, O.M.R. (2017) The Landscape of Cesarean Sections in Sub-Saharan Africa and South and Southeast Asia. Fistula Care Plus, New York. https://fistulacare.org/

[7] Bishop, D., Dyer, R.A., Maswime, S., et al. (2019) Maternal and Neonatal Outcomes after Caesarean Delivery in the African Surgical Outcomes Study: A 7-Day Prospective Observational Cohort Study. The Lancet Global Health, 7, e513-e522. https://doi.org/10.1016/S2214-109X(19)30036-1

[8] Dujardin, B., Delvaux, T. and De Bernis, L. (1998) La césarienne de qualité, analyse des déterminants. Actes du 5 eme congrès de la SAGO (Société Africaine de Gynécologie et d'Obstétrique), Dakar, Sénégal. Cahiers de Santé, 8, 369-377.

[9] Mongbo, V., Ouendo, E.M., De Brouwere, V., et al. (2016) La césarienne de qualité : Etude transversale dans 12 hôpitaux au Bénin. Revue d Epidémiologie Santé Publique, 64, 281-293. https://doi.org/10.1016/j.respe.2016.02.009

[10] Ouedraogo, C., Zoungrana, T., Dao, B., et al. (2001) La césarienne de qualité au Centre Hospitalier Yalgado Ouedragogo de Ouagadougou Analyse des déterminants à propos de 478 cas colligés dans le service de gynécologie obstétrique. Médecine d Afrique Noire, 48, 443-450.

[11] Tebeu, P.M., Mboudou, E.T., Halle-Ekane, G., et al. (2011) Risk Factors of Delivery by Caesarean Section in Cameroon (2003-2004): A Regional Hospital Report. International Scholarly Research Notices, 2011, Article ID: 791319.

https://doi.org/10.5402/2011/791319 
[12] Tebeu, P.M., Ngassa, P., Mboudou, E.T., Kongnyuy, E.J., Binam, F. and Abena, M.T. (2008) Neonatal Survival Following Cesarean Delivery in Northern Cameroon. International Journal of Gynecology and Obstetrics, 103, 259-260. https://doi.org/10.1016/j.ijgo.2008.07.001

[13] Njim, T., Choukem, S.P. and Mbu, R. (2017) Cesarean Sections in a Secondary Level Care Hospital of Cameroon: An Analysis of Their Six-Year Trends and Adverse Neonatal Outcomes. BMC Research Notes, 10, Article No. 430. https://doi.org/10.1186/s13104-017-2750-2

[14] Ngowa, J.D.K., Ngassam, A., Fouogue, J.T., Metogo, J., Medou, A. and Kasia, J.M. (2015) Complications maternelles précoces de la césarienne: A propos de 460 cas dans deux hôpitaux universitaires de Yaoundé, Cameroun. Pan African Medical Journal, 21, Article ID: 265. https://doi.org/10.11604/pamj.2015.21.265.6967

[15] Foumane, P., Mve, K.V., Minkande, Z.J., Njofang, N.E.A., Dohbit, J.S. and Mboudou, E.T. (2014) Risk Factors and Prognosis of Emergency Cesarean Delivery at the Yaoundé Women's and Children's Hospital, Cameroon. Médecine et Santé Tropicales, 24, 89-93. https://doi.org/10.1684/mst.2014.0307

[16] Dikete, M., Coppieters, Y., Trigaux, P., Englert, Y., Simon, P. and Zhang, W. (2019) An Analysis of the Practices of Caesarean Section in Sub-Saharan Africa: A Summary of the Literature. Archives of Community Medicine and Public Health, 5, 77-86. https://doi.org/10.17352/2455-5479.000058

[17] Dekker, L., Houtzager, T., Kilume, K., Horogo, J., Roosmalen, J.V. and Nyamtema, A.S. (2018) Caesarean Section Audit to Improve Quality of Care in a Rural Referral Hospital in Tanzania. BMC Pregnancy and Childbirth, 18, Article No. 164. https://doi.org/10.1186/s12884-018-1814-1

[18] Richard, F., Ouedraogo, C. and Brouwere, V.D. (2008) Quality Cesarean Delivery in Ouagadougou, Burkina Faso: A Comprehensive Approach. International Journal of Gynecology and Obstetrics, 103, 283-290. https://doi.org/10.1016/j.ijgo.2008.08.008

[19] Kabore, C., Ridde, V., Kouanda, S., Agier, I., Queuille, L. and Dumont, A. (2016) Determinants of Non-Medically Indicated Cesarean Deliveries in Burkina Faso. International Journal of Gynecology and Obstetrics, 135, S58-S63. https://doi.org/10.1016/j.ijgo.2016.08.019

[20] Kruk, M.E., Wladis, A., Mbembati, N., et al. (2010) Human Resource and Funding Constraints for Essential Surgery in District Hospitals in Africa: A Retrospective Cross-Sectional Survey. PLoS Medicine, 7, e1000242.

https://doi.org/10.1371/journal.pmed.1000242 


\section{Abbreviations}

$\begin{array}{ll}\text { aOR: } & \text { Adjusted Odds Ratio } \\ \text { cOR: } & \text { Crude Odds Ratio } \\ \text { CS: } & \text { Cesarean Section } \\ \text { DDH: } & \text { Dschang District Hospital } \\ \text { PMDH: } & \text { Penka Michel District Hospital } \\ \text { SD: } & \text { Standard Deviation } \\ \text { SPSS: } & \text { Statistical Package for Social Sciences } \\ \text { SSA: } & \text { Sub-Saharan Africa } \\ \text { SVPH: } & \text { Saint Vincent de Paul Hospital } \\ \text { UHC: } & \text { Universal Health Coverage } \\ \text { USD: } & \text { United States Dollars } \\ \text { WHO: } & \text { World Health Organisation }\end{array}$

